\title{
The risk-based approach in organization quality management systems
}

\author{
Oksana V. Zhemchugova / Violetta V. Levshina* \\ Reshetnev Siberian State University of Science and Technology - Faculty of Economics and Business \\ Processes Management - Russia
}

Received: 17 January 2020 / Accepted: 8 June 2020

\begin{abstract}
The relevance of the study is associated with the problem of introducing a risk-based approach in the quality management systems (QMS) of organizations from various sectors according to the requirements of ISO 9001:2015. It hereby offers a new feature of risk classification based on their application in management systems concerning various aspects of organizations activity, in particular, risk in QMS (quality risk). The authors' definition of the term "quality risk" is presented, and the concept of the "risk-based approach in QMS" is clarified. Methodical approaches to the choice of the complexity of the risk-based approach depending on the QMS maturity in an organization and the factors of its environment are developed and tested in 46 organizations from various industries.
\end{abstract}

\section{Keywords}

ISO 9001:2015 / Risk-based thinking / Quality management system / Quality risk / Organizational environment / Maturity of the quality management system.

\section{0 enfoque baseado no risco nos sistemas de xestión de calidade das organizacións}

\section{Resumo}

A relevancia do estudo está asociada co problema de introducir un enfoque baseado no risco nos sistemas de xestión de calidade (SXC) de organizacións de diversos sectores de acordo cos requisitos da norma ISO 9001:2015. Ofrécese un novo criterio de clasificación de riscos baseado na súa aplicación en sistemas de xestión en relación con diversos aspectos da actividade das organizacións, en particular o risco en SXC (risco de calidade). Preséntase a definición dos autores do termo "risco de calidade" e aclárase o concepto do "enfoque baseado no risco no SXC". O enfoque metodolóxico para a elección da complexidade do enfoque baseado no risco, dependendo da madureza do SXC nunha organización e dos factores do seu medio, desenvólvense e próbanse en 46 organizacións de diversas industrias.

\section{Palabras clave}

ISO 9001:2015 / Pensamento baseado en riscos / Sistema de xestión de calidade / Risco de calidade / Medio organizacional / Madureza do sistema de xestión de calidade.

Códigos JEL: D81, M1, M11

\section{Introduction}

When designing a Quality Management System (QMS) of an organization according to ISO 9001:2015 requirements, it is necessary to apply the concept of a risk-based approach as well as ensure its use in planning actions with regard to risks and various opportunities. This approach helps increase the efficiency of organizations and improves their quality of services by preventing inconsistencies in all processes of their QMS.

As noted by Orlova (2018), risks exist in all areas of human activity and socio-economic communities, and the theory of risk refers to interdisciplinary science. According to Hutchins (2014),

${ }^{*}$ Corresponding author: levshina.rssu@bk.ru 
risk management is the future of quality management, which is reflected in the new version of the ISO 9000 standard. They pay particular attention to the risk-based approach in the QMS of organizations. According to the reference literature (Abernathy, 2016; Akimov, 2004; Batova, 2015; Cagnin, Oliveira and Cauchick Miguel, 2019; Chaika, 2014; Crocker and Snow, 2018; Itkin, 2016; Levshin, 2015; Ralexandrov, Timofeeva, Zorin and Novikov, 2017; Rybski, Jochem and Homma, 2017), in addition to obtaining information from quality service specialists, organizations have issues in implementing the risk-based approach and in passing audit procedures (internal and external) when transitioning to ISO 9001-2015 requirements. This is due to the lack of consistency in the conceptual framework and procedures between stakeholders, including the managers and employees of organizations and the internal and external auditors. As a result, organizations often try to formalize the selected approaches to the application of the risk-based approach in their QMS, sometimes even redundantly. Therefore, our goal is the definition and clarification of some terms in the field of risk management as well as the development and testing of methodological approaches regarding the choice of the risk-based approach in the QMS of organizations in various industries, depending on their characteristics.

In the study conducted by Orlova (2018), as well as in a number of other works (Abernathy, 2016; Akimov, 2004; Balabanov, 1997; Balme, 2015; Batova, 2015; Crocker and Snow, 2018; Crouhy, 2018; Durivage, 2017; Hoodat and Rashidi, 2009; Hopkin, 2017; Itkin, 2016; Mire-Sluis et al., 2010; Renn, 2010; Vaz Pereira, Severo and Fontoura, 2016), it is shown that there is currently no clear classification of risks. Existing classifications are often based on the following attributes of classification: The degree of influence, object, subject (source), and reason for origin, the field of activity, and the organizational environment, among others. However, there is no mention among these about the sign of risk classification according to their application in management systems concerning the various aspects of organizations; this, in our opinion, should be introduced into scientific circulation. This is due to the development of international standardization in the field of management systems, namely, the introduction of a single approach to the development and revision of standards for management systems ("high-level structure"). New versions of ISO 9001, ISO 14001, and ISO 45001 standards have appeared on the basis of this, and each of them contains risks: risk in QMS (quality risk), risk in the environmental management system (environmental risk), risk in the health, safety, security, and environment system (HSSE risk), and others.

Despite the fact that the term "quality risk" is used in various works (Barafort, Mesquida and Mas, 2018; Dzedik, 2015; Fonseca and Domingues, 2018; Hoodat and Rashidi, 2009; Panasyuk, 2015; Spiridonova and Khomutova, 2017; Ukolov, 2017) there is no definition of the term "quality risk" in the scientific and normative literature that can be used in the QMS of organizations. In the GOST R ISO 9000-2015 standard, the term "risk" refers to one of the general terms and definitions for ISO standards on management systems; it is interpreted as the "influence of uncertainty" and can be extended to any management system of organizations. However, the term "risk", which takes into account the peculiarities of the QMS, namely "risk in the field of quality", requires a specification similar to other management systems (GOST R ISO 14001-2016, ISO 45001:2018), in which the interpretation of the relevant term "risk" is normatively fixed (GOST R 57189-2016/ISO/TS 9002:2016, 2016; GOST R ISO 9001-2015, 2015).

To define the term "quality risk", we base on the standard, wherein the term "risk" is presented as "the impact of uncertainty on objectives". Previous authors (Hoodat \& Rashidi, 2009; Rybski et al., 2017) also interpret risk as "an event that impedes the achievement of objectives" and highlight the key word in the definition of risk - an "objective". Performance indicators are defined in accordance with the objectives, on the basis of which possible events (risks) impeding their achievement are identified. Redko and Yanushevskaya (2018) believe that the main purpose of QMS is to meet the requirements of consumers (in terms of quality, cost, timing of production, availability of goods, level of after-sales service, etc.). In the work of Orlova (2018), the main designated task of a QMS is also to ensure the sustainable development of an organization to achieve its goals in the field of quality.

In connection with the above, we propose introducing into the scientific circulation the definition of the term "quality risk" as "the impact of uncertainty on the achievement of quality objectives aimed at 
ensuring the sustainable development of an organization through a balanced satisfaction of the requirements of its stakeholders". Its novelty lies in the specification of the general term "risk" and its definition in relation to the peculiarities of the QMS of an organization, its objectives in the field of quality, its main task in ensuring the sustainable development of the organization, and its focus on interests of stakeholders.

The widely used term "risk-based approach" is currently not universally accepted. The definitions of this term used in the majority of scientific publications (Molach, Long \& Bisman, 2015; Smith, Kourouklis \& Cano, 2018; Crocker \& Snow, 2018; Itkin, 2016) do not take into account the peculiarities of its application in QMS. Therefore, we propose a more precise concept of the term "risk-based thinking in QMS". This is a "qualitative and/or quantitative assessment of the quality risks arising from the organizational environment, and also decision-making to prevent or reduce undesirable consequences and to maximize the use of opportunities in the organization processes and QMS as a whole to achieve their effectiveness". This integrates and supplements the definitions presented in the works of Chaika (2014) and Golubinsky (2016). The novelty of the "risk-based approach in QMS" concept proposed by us consists of limiting its application to only the QMS of an organization and, consequently, the risks in the field of quality. It is emphasized that their source is the environment of the organization and its stakeholders as an integral part of this environment, which is especially necessary at the stage of risk identification. The decision-making objectives regarding the approach to process management and the QMS are expanded. They are the prevention or reduction of undesirable consequences and the maximum use of emerging opportunities as well as the achievement of the efficiency of processes and the QMS as a whole. Qualitative risk assessment means the identification of quality risks; quantitative assessment is the determination of their level of significance, for example, critical, significant, or acceptable risk.

To date, methodological studies by various authors (Balabanov, 1997; Crouhy, 2018; Durivage, 2017; Mire-Sluis et al., 2010; Panasyuk, 2015; Ralexandrov et al., 2017; Smith et al., 2018; Ukolov, 2017) offer the implementation of the risk-based approach by various methods - from the simplest methods to the formalized risk management methods (according to ISO 31000:2018 and GOST R ISO 31010-2010). Taking into account their specificities, the literature does not classify these methods in terms of their complexity or applicability (suitability) to different types of organizations, although it is known that some methods and tools have been used for many years in certain industries, such as the automotive industry (FMEA), medical devices industry (FMECA), and food industry (HACCP). Risk management methods (ISO 31000) have been introduced in a number of high-tech industries and services (aerospace and telecommunications, nuclear power, healthcare, and banking) at the request of stakeholders (Mire-Sluis et al., 2010). Therefore, the use of the risk-based approach in the QMS in these industries does not cause difficulties, unlike in most other areas of activity, including services as well as small business organizations.

Therefore, an organization itself must determine which risk-based approach it will use, and there is a problem in justifying this choice. To provide a solution, we put forward a hypothesis that the risk-based approach in a QMS can be applied in any organization, irrespective of size and the sector profile, but the complexity of the methods of its application depends, essentially, on the environment of the organization, including the internal environment, and considering the maturity of its processes and QMS as a whole.

The first part of this hypothesis is based on the standard ISO 9001-2015, in which (item 6.1) the requirements on the planning of actions concerning risks and possibilities are stated; it is also specified (item 1) that the scope of application of the standard includes any organization irrespective of its kind, size, delivered production, and services provided. It should be emphasized that the new QMS model of an organization does not require the introduction of risk management according to ISO 31000:2018, although this standard can also be applied to any organization and its environment. However, unlike the standard ISO 9001-2015, it does not emphasize its use in organizations, regardless of their size, for example, small businesses. The standard ISO 31000:2018 specifies that the 
risk management process can have many application options adapted to the need to achieve the goals of an organization, as well as its external and internal environment, but it is difficult to implement its methodological approaches in small organizations.

The second part of the hypothesis highlights the complexity of the risk-based approach. Recommendations (Levshin, 2015) indicate that an organization can choose the methods that are appropriate for its needs using the international standard ISO/IEC 31010-2009, which can be applied depending on the environment of the organization.

It has been established that the external environment of an organization is conditioned by the impact of various factors related to the legislative, technological, competitive, market, cultural, social, and economic environment at the international, national, regional or local level. The internal environment is, first of all, characterized by the maturity of the established management systems of the organization, including the QMS and risk management systems. Therefore, the application of a complex method of the risk-based approach in an organization is connected with the external environment that promotes it as well as with the internal environment that provides this process. The latter is the mature QMS of the organization and the human factor corresponding to it.

Thus, there are different methods of applying the risk-based approach, which can be divided into levels of complexity. In our research, we have conventionally identified them as $A$ - the simplest method (e.g. based on defining quality objectives and planning changes in QMS); B - the medium complexity method (using risk management elements); and C - the high complexity method (according to ISO 31000). However, there is a problem in how to determine which complexity for the methods of applying the risk-based approach in the QMS should be chosen for a particular organization. To solve this problem, it is necessary to develop methodological approaches to the choice of the risk-based approach in the QMS in an organization, taking into account its peculiarities, and to test them.

\section{Methods}

In order to achieve the above-mentioned goal, the first research stage involved selecting the most important classification characteristics of organizations, which would be later used to select the complexity of the risk-based approach in the QMS. For this purpose, having based on the known characteristics of the organizational environment, we compiled an approximate list of the classification characteristics of an organization, divided into two groups.

The first of these included 7 classification characteristics determined by the external environment of an organization, while the second one was its internal environment ( 21 characteristics). An expert group was created, consisting of 10 heads of quality services of enterprises as well as 10 teachers of quality management departments from various universities, having experience of consulting and expert activity in organizations of various industries. The experts assessed the significance of each organizational classification characteristic from the point of view of its influence on the complexity choice of the risk-based approach for the QMS. A five-point scale was used: 5 - strong influence; 4 significant influence; 3 - normal influence; 2 - weak influence; 1 - no influence. The consistency of the experts' work was assessed using the concordance coefficient and its significance based on the Pearson criterion. The concordance coefficient was established as 0.67 . The calculated value of the Pearson criterion was $\chi^{2}=359.62$, which is higher than $\chi_{\text {table }}^{2}=40.113$ (at the $\alpha=0.05$ significance level), thus confirming the expert's group work consistency.

Thus, for each classification characteristic, the average value of its influence on the choice of the risk-based approach was calculated. The significance range for the classification characteristics of the organization was from 2.7 to 4.7 points. As a result, all 28 classification characteristics studied were divided into three groups according to the level of their significance: The first group - from 4.0 to 4.7 points; the second - from 3.2 to 3.9 (Table 1); and the third - less than 3.2. 
Table 1. Significant classification characteristics of the organization

Group 1 (value from 4.0 to 4.7 )

Group 2 (value from 3.2 to 3.9)

Characteristics related to the external environment of the organization

Legislative and regulatory requirements

Consumer requirements for product quality and supply

Availability of competitors in the market segment
Socio-economic factors

Requirements of the founders of the organization

Characteristics of suppliers of raw and other materials, components, and services

Characteristics related to the internal environment of the organization

The willingness of the organization leaders to apply the risk-based approach

Features of finished products (services) in terms of the risk-based approach

Maturity of the QMS

Level of sophistication of the technologies used

Level of qualification and competencies of managers and specialists

Level of qualification and competencies of the employees
Industry affiliation and its features

Completeness of the product life cycle used

The difficulty level of the equipment used

Ageing of the main equipment

Maturity of the motivation system

Level of the communication system in the organization

Availability of the outsourced processes in the organization

Availability of the organizational strategy

Source: own elaboration.

The third group included mainly the classification characteristics related to the internal environment: "Product variety"; "Complexity and size of the organization"; "Age of the organization"; "Number and complexity of the measuring instruments used"; "Staff turnover"; "Features of the production environment"; "Results of the competitive environment analysis"; as well as one characteristic related to the external environment - "State of the labor market".

The expert method stated not to use the third group of classification characteristics as the less significant ones (i.e. less than 3.2 points). 1) "Sector profile of the organization and its features" as having a logical connection with the characteristic of the first group - "Legislative and regulatory requirements"; and 2) "Complexity of the main equipment used" logically related to the characteristic of the first group - "Complexity of the applied technologies" (Table 1; the characteristics excluded are given in italics). Based on the method given by the experts, it was decided not to use the third group of classification characteristics as these are the least significant (i.e. less than 3.2 points).

The checklist was developed based on significant classification characteristics (Table 1, as an example) to assess the state of the organization environment in order to select the complexity for the risk-based approach in the QMS (methods A, B, C). According to our proposed methodology, an organization can assign several staff members to act as experts and assess the state of the environment based on the classification characteristics, noting this assessment with a sign on a checklist (Table 2). It was assumed that a high degree of implementation corresponds to 9 points, while medium is 3 and weak is 1. 
Table 2. Assessment of the classification characteristics implementation degree in LLC "Progress" (fragment)

\begin{tabular}{|c|c|c|c|}
\hline \multirow{2}{*}{ Classification characteristic of the organization } & \multicolumn{3}{|c|}{ Implementation degree } \\
\hline & High & Medium & Weak \\
\hline \multicolumn{4}{|l|}{ The first group of classification characteristics } \\
\hline $\begin{array}{l}\text { 1. Legislative and regulatory requirements for products and the organization itself } \\
\text { 2. Consumer requirements for product quality and supply } \\
\text { 3. Availability of competitors in the market segment } \\
\text { 4. The willingness of the organization leaders to apply risk-based thinking } \\
\text { 5. Features of the products (services) in terms of risk-based thinking } \\
\text { 6. Maturity of the QMS } \\
\text { 7. The difficulty level of the technologies applied } \\
\text { 8. The level of qualifications and competencies of managers and specialists } \\
\text { 9. The level of qualifications and competencies of performers }\end{array}$ & $\mathrm{X}$ & $\begin{array}{l}X \\
X \\
X \\
X \\
X\end{array}$ & $\mathrm{X}$ \\
\hline \multicolumn{4}{|l|}{ The second group of classification characteristics } \\
\hline $\begin{array}{l}\text { 1. Socio-economic factors } \\
\text { 2. The founders' requirements } \\
\text { 3. Characteristics of suppliers of raw materials, components, and services } \\
\text { 4. The completeness of the applied product life cycle } \\
\text { 5. The equipment age } \\
\text { 6. The maturity of the motivation system } \\
\text { 7. Organization communication system level } \\
\text { 8. Outsourced organization processes } \\
\text { 9. Whether the organizational strategy is developed or not }\end{array}$ & $\mathrm{X}$ & $\begin{array}{l}X \\
X \\
X\end{array}$ & $\begin{array}{l}X \\
X\end{array}$ \\
\hline
\end{tabular}

Source: own elaboration.

To obtain a final assessment of the complexity for the risk-based approach method, we proposed a comprehensive indicator $G$, which was calculated by the organization's experts according to the following formula

$$
G=1.2\left(9 n_{1}+3 n_{2}+n_{3}\right)+\left(9 m_{1}+3 m_{2}+m_{3}\right),
$$

where $n_{1}, m_{1}$ are the numbers of classification characteristics for the first and second groups with a high degree of implementation, respectively; $n_{2}, m_{2}$ are the same for the medium degree; and $n_{3}, m_{3}$ are the same for the weak degree.

In the complex indicator formula, the weights were determined taking into account the level of their significance value (Table 1): for the first group of classification characteristics 1.2 , and for the second group 1.0. It was calculated that the maximum value of $G$ is 178.2 , and the minimum value is 19.8.

For an organization, we offer a scale based on which its experts can choose the complexity for the risk-based approach in the QMS. Specifically, if $G$ is equal to or greater than 120 , then complex method $C$ is recommended; if $G$ is between 62 and 120, method B is recommended for medium complexity; and if $G$ is equal to or less than 62, the organization may use the simplest method A.

\section{Results}

In order to test the methodological approaches to the choice of the risk-based approach for the QMS of an organization, we formed a random sample of 46 large, medium and small-sized organizations from 
various industries as the objects of the study. In order to comply with confidentiality requirements, we do not give the name of the organizations used in the research. With regard to their size, the organizations were divided into three groups according to the risk-based approach (methods A, B, C) (Table 3). The results are presented starting with method $\mathrm{C}$ as the most formalized.

Table 3. The integrated indicator G values for organizations of different industries

Method C - high complexity application of the risk-based approach

\begin{tabular}{lr}
\hline Manufacture of building materials (cement) & 138 \\
Development and production of communication means, equipment, and systems & 144 \\
Development and manufacture of equipment for oil pipelines & 125 \\
Development and production of mining machinery and equipment; aircraft testing and repair & 143 \\
Wholesale and retail sale of pharmaceutical and medical products & 125 \\
Public road construction services & 122 \\
Higher professional education (medical) & 134 \\
Design and production of electrical devices & 126 \\
Transportation of passengers and luggage by air (organization number 1) & 128 \\
Transportation of passengers and luggage by air (organization number 2) & 142 \\
Food testing & 130
\end{tabular}

Method B - medium complexity of the risk-based approach

Production of non-ferrous metals 108

Development of formulations and production of elastic polyurethane foam $\quad 97$

Carrying out scientific, technical, design and survey work in the field of geological exploration, $\quad 104$

development, field development and production of hydrocarbons

Higher professional education (organization number 1) 101

Higher professional education (organization number 2) 97

$\begin{array}{ll}\text { Secondary vocational education } & 104\end{array}$

Training and certification of occupational safety and health and environmental protection $\quad 67$

organization employees

Preparation of design documentation for capital construction facilities; industrial safety expertise $\quad 66$

Engineering, geo-navigation; software development and technical support for oil and gas companies $\quad 85$

Preparation of project documentation affecting the safety of capital construction facilities

Provision of wholesale and retail services in the field of automotive parts, assemblies and accessories $\quad 68$

Engineering and technical design, testing and research in the field of construction; geodetic and 111

cartographic activities, and industrial safety expertise

Development and execution of engineering surveys, including a survey of soils under foundations of 116

buildings and structures

Performing works on standardization and metrological support $\quad 80$

Housing and communal services management $\quad 63$

Land improvement works during construction $\quad 112$

$\begin{array}{lc}\text { Provision of social services in the pension fund } & 68\end{array}$

Provision of public services in multifunctional centers $\quad 103$

Design and manufacture of windows $\quad 116$

$\begin{array}{lr}\text { Banking services } & 100\end{array}$

Telecommunication services $\quad 94$

$\begin{array}{ll}\text { Retail services } & 82\end{array}$

$\begin{array}{ll}\text { Fire tests and fire safety review } & 72\end{array}$

Distribution services $\quad 91$

Sheet glass recycling 101

$\begin{array}{ll}\text { Municipal management services } & 87\end{array}$ 
Table 3 (continuation). The integrated indicator G values for organizations of different industries

\begin{tabular}{lc}
\hline \multicolumn{1}{c}{ The main activity of an organization } & $G$ \\
\hline Method A - the simplest method of the risk-based approach & 38 \\
\hline Repair of household appliances & 55 \\
Baking and sale of bakery products & 45 \\
Health and fitness services & 33 \\
Cleaning services for vehicles & 41 \\
Growing medicinal herbs & 47 \\
Social assistance to families and children & 56 \\
Window design and development & 51 \\
Advertising services & \\
\hline
\end{tabular}

Source: own elaboration.

Quantitative analysis of the results showed that for the majority of the organizations (56\%) from the random sampling, method $B$, related to the medium complexity of the risk-based approach, is the most appropriate; the high complexity method (method C) can be applied by $20 \%$ of organizations; and the simplest method A can be applied by $18 \%$.

As a result of the qualitative analysis of organizations, it was established that group $\mathrm{C}$ (high complexity method) is represented mainly by large organizations in the fields of mechanical engineering, communications, cement industry, wholesale and retail sale of medicines and medical products, state management of road construction, transportation of passengers and luggage by air, higher professional medical education, and testing of food products. This is due to the fact that, as a rule, these organizations are subject to the strong impacts of environmental factors, including numerous legislative and regulatory requirements for the products of these organizations and their QMS, high (mainly formalized) consumer requirements, a strong competitive environment, and socioeconomic factors such as sanctions, crises, a decline in purchasing power as well as numerous suppliers of raw materials, services and components, with whom it is necessary to develop mutually beneficial relationships. For more than 5 years, all the organizations under study have been developing QMS in accordance with the requirements of ISO 9001, and many of them have developed and implemented sectoral QMS and other management systems (ISO 14001, OHSAS 18001). These organizations differ from others by the presence of leaders who are willing to apply the risk-based approach as well as by the availability of qualified managers and specialists.

Group B (medium complexity methods) includes mainly medium-sized organizations related to the chemical industry, production of rare non-ferrous metals, higher and secondary vocational education (except for medical education), additional professional education, construction (design activities, research, construction, expert appraisal, etc.), information technology (geonavigation, engineering, software), wholesale and retail trade in automotive parts and components, as well as the provision of various types of other services.

These organizations are characterized by the high requirements of consumers and founders, the presence of strong and numerous competitors, and the impacts of socio-economic factors (crises, decline in the purchasing power of the population). Educational organizations are regulated by a large number of legislative and regulatory requirements. Almost all organizations included in this group are headed by aggressive and qualified managers, ready to informally develop the QMS in accordance with modern requirements.

The third group A (the simplest method of applying the risk-based approach in QMS) unites small business organizations mainly related to the service sector (e.g., repair of household appliances, health and fitness services, cleaning, social, housing and communal services) as well as the agricultural sector (cultivation of medicinal plants), food (baking and sale of bakery products), woodworking (design and 
production of windows), and other sectors. Consumers of these organizations have high requirements, the organizations have competitors, and the activities of the organizations are influenced by socio-economic factors (for example, the low purchasing power of the population). Not all leaders of these organizations demonstrate leadership qualities, and they lead specialists and workers who are not always highly qualified. These organizations have no QMS in accordance with the requirements of ISO 9001, but most of them are concerned with quality problems in order to survive in their markets. Therefore, these organizations should be gradually educated and involved in the application of modern quality management principles and approaches.

\section{Discussion}

Analyzing the above-presented classification characteristics of the organizations, we divide them into two groups:

1) Classification characteristics related to the environment. These are sources of environmental risks and promote the organization to the implementation of risk-based thinking; they are: "Legislative and regulatory requirements to products and organizations", "Consumer requirements to product quality and supply", "Availability of competitors in the market segment", "Requirements from the founders of the organization", "Socio-economic factors", and "Characteristics of suppliers of raw and other materials, components and services". It should be noted that there is a direct correlation: the higher the evaluation of these classification characteristics, the more complex the method of applying the risk-based approach should be used by the organization.

2) Classification characteristics related to the internal environment of an organization. These are sources of risks to the internal environment of the organizations. We have identified three subgroups:

-Those combining classification characteristics due to production processes. These are "Features of products (services) in terms of risk-based approach", "Complexity of applied technologies", "Completeness of applied product life cycle", "Main equipment ageing", and "Availability of outsourced processes in the organization". There is also a direct correlation between the evaluation of these classification characteristics and the complexity of the risk-based approach.

-Those combining the classification characteristics associated with the human factor. These are the "Readiness of the leaders of the organizations to apply the risk-based approach", "The level of qualification and competencies of managers and specialists", and "The level of qualification and competencies of workers". In addition to the fact that these classification characteristics initiate organizational risks, they also provide for the successful application of the risk-based approach. That is, the higher the value of their assessment, the more complex risk-based approach can be applied, and vice versa, whereby the lack of leadership in the organization and the low qualification of managers and employees restrain the use of a complex method of the risk-based approach.

-Those combining classification characteristics related to the management system of the organization. These are "Maturity of the QMS in the organization", "Maturity of the motivation system", "Level of the communication system in the organization", and "Availability of the organizational strategy".

The characteristic "Maturity of the QMS in the organization" is comprehensive and includes many characteristics related to different aspects of the organizational activities and their results. This is reflected in the organization's self-assessment criteria presented in the recommendations of ISO 9004. As a rule, the maturity of QMS in an organization is connected with its age, but only in the case of the informal introduction of standard ISO 9001 requirements. The higher the maturity of the QMS, the more complex method of the risk-based approach can be used in an organization. 
However, the value of the other three classification characteristics is inversely related to the complexity of the risk-based approach. Namely, the higher the maturity of the personnel and the management motivation system, for example, the implementation of the KPI system, the less likely the risks associated with the human factor will arise. If the information transfer process is complicated and/or a corporate information system is absent, communication barriers in the organization occur. The availability of an informal organizational strategy reduces the likelihood of risks occurring, so simpler ways of applying the risk-based approach can be used.

Based on the abovementioned, we have developed a model for the risk-based approach evolution of QMS depending on the main factors: QMS maturities of the organization and its environment. The model includes three methods of applying the risk-based approach at different levels of complexity: A, $B, C$. The stages of each method can be distributed according to the Deming management cycle (PDCA) as quality risk management is applied in all these methods. For the simplest method A, the PDCA cycle phase value will be significantly lower than for the corresponding steps for the most complex method C, which is based on the ISO 31000:2018 standard. Method B is in a "floating" and intermediate position, but it can be assumed that it contains the phase P ("plan") to a greater extent and the phase A ("act") to a lesser extent. The model reflects that the transition from method A to method C is mainly due to the QMS maturity in the organization (as the main factor of its internal environment) and environmental factors. The "QMS maturity in the organization" characteristic ensures the application of the risk-based approach. The factors of the external environment of the organization reflected in the classification characteristics, such as "Legislative and regulatory requirements for products and organization", "Consumer requirements for the quality of products and their supply", and "Presence of competitors in this market segment", initiate and promote the organization in the development of the risk-based approach.

It follows from the presented model (Figure 1) that the risk-based approach in organizations with a high level of maturity can evolve to the integration of two organization management systems - QMS and the risk management system (ISO 31000). According to Orlova (2018), the latter reflects the general management functions and applies to all functional areas. The risk management system, like any other system, can also be of different levels of maturity, so we can assume that an organization, such as a small business, can initially apply the simplest risk-based approach (because its human factor is not matured, and its head, above all). But, as the system develops and the effectiveness of the risk-based approach is understood, the organization can move to a more complex and effective method, for example, one of medium complexity, and which it can implement together with the modern QMS. When an organization management system performs the transition to a higher level of maturity to develop methods of the in-depth application of the risk-based approach, it can use the recommendations of ISO 31000:2018 and ISO/IEC 31010-2009, that is, the development of a risk management system.

This model does not reflect the impact of organization size. This is confirmed by the low value of the expert evaluation of the qualification characteristic "Complexity and size of the organization" (3.1 points), as a result of which it was removed from the checklist (Table 2). In addition, as the results of our testing have shown, method A is suitable for small organizations, but, if the appropriate conditions arise, such organizations may move to the more complex method B. Medium to large organizations with low QMS maturity can also begin to apply the risk-based approach with the simplest method A and move on to more complex methods. It should be noted that the size of an organization, as a rule, is associated with their sector profile (for example, services, high-tech production) and their impact on the application of the risk-based approach in the QMS of similar organizations will be similar, too.

All of the above confirms the hypothesis that we put forward about the application of the risk-based approach in the QMS of organizations regardless of their size and sector profile, and it concretizes the influence of the QMS maturity of an organization and the factors of its environment on the choice of the complexity for the methods used. 


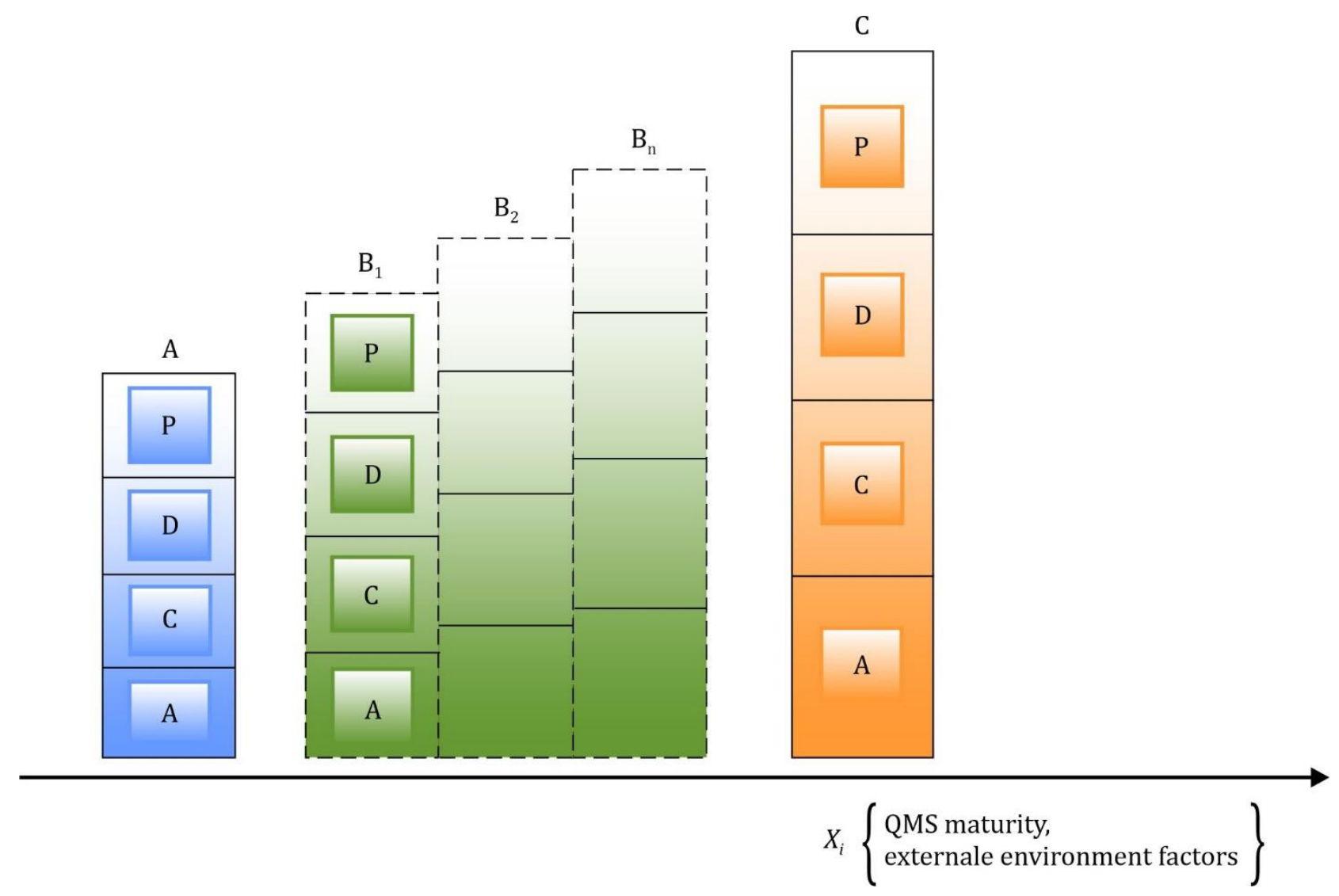

Figure 1 - Evolution model of the risk-based approach in QMS with different complexity methods (A, B, C) depending on the QMS maturity in an organization and its environment.

The results presented in this paper differ from our earlier works (Zhemchugova and Levshina, 2018; Zhemchugova, Levshina and Levshin, 2017) by a significantly expanded (by 50\%) random sample of organizations. This allowed us to improve the methodological approaches to solve the set goal. We have not found any similar research in this area.

The importance of our research lies in its practical use in organizations of various sectors facing the choice of the optimal method in applying the risk-based approach in their QMS. The authors propose the feature of risk classification, the new definition of the term "quality risk", and a more precise definition of the term "risk-based approach in the QMS". Their proposals are based on the international regulatory framework and contribute to the development of the terminological apparatus of risk management and the theory of organizational systems in relation to quality management.

The disadvantages of the research include the influence of subjectivity inherent in the expert methods used in the work, which is reflected in the list of the qualification characteristics of the organization (Table 1) and the proposed formula of the complex indicator $G$. However, the recommendations provided can serve as a clear guideline for organizations when choosing a riskbased approach for their QMS, taking into account the specifics of their organizational environment.

\section{Conclusions}

It is known that organizations face difficulties in implementing the risk-based approach in accordance with the requirements of ISO 9001:2015. To solve this problem, we made proposals for the 
development of terminology in the field of risk theory, taking into account the development of international standardization in the field of management systems. A new feature of risk classification is presented by their application in the management systems concerning various aspects of organizational activities, combining risk in the QMS (quality risk), risk in the environmental management system (environmental risk), and others. The authors' definition of the term "quality risk" is given, and the concept of "risk-based approach in the QMS" is clarified. This terminological apparatus was used in the development and testing of methodological approaches regarding the complexity choice for the method of applying the risk-based approach in an organization. The organizational environment factors served as the basis for the development of the list of classification characteristics for an organization, from which the most significant ones were identified with the use of the expert method. The method of choosing the complexity for the risk-based thinking, based on the determination of the complex index value, which includes significant classification characteristics of an organization, was proposed. This method was tested in 46 organizations from various sectors. It was established that the risk-based approach in QMS can be applied in the organizations irrespective of their size and sector profile, but the QMS maturity of the organization and factors of its environment have the greatest influence on the complexity of the methods used. The evolution model for the riskbased approach in QMS depending on the size of the organization with those classification characteristics is presented. Further aspects of the study will be aimed at identifying and testing risk-based approach techniques with various complexities in the QMS of organizations of various sectors.

\section{References}

Abernathy, C. (2016). Embracing the quality risk management process as a means to a strong quality culture. Retrieved from: https://www.outsourcedpharma.com/doc/embracing-the-quality-risk-managementprocess-as-a-means-to-a-strong-quality-culture-0001

Akimov, V.A. (2004). Risks in nature, technosphere, society, and economy. Moscow, Russia: Business Express.

Balabanov, I.T. (1997). Risk management. Moscow, Russia: Unity.

Balme, D. (2015). ISO 9001:2015: A key lever to take up the challenges of deregulated markets, change of consumption habits and make the best use of technological breakthroughs. Asigurarea Calităţii-Quality Assurance, 21(83), 23-25. Retrieved from: http://www.euroqual.pub.ro/wp-content/uploads/83-23.pdf

Barafort, B., Mesquida, A., \& Mas, A. (2018). ISO 31000-based integrated risk management process assessment model for IT organizations. Journal of Software: Evolution and Process, 31(1). DOI: https://doi.org/10.1002/smr.1984

Batova, I. B. (2015). Classification of risks and their causes. International Student Scientific Bulletin. Retrieved from: https://www.eduherald.ru/pdf/2015/1/25.pdf

Cagnin, F., Oliveira, M. C., \& Cauchick Miguel, P. A. (2019). Assessment of ISO 9001: 2015 implementation: Focus on risk management approach requirements compliance in an automotive company. Total Quality Management \& Business Excellence. DOI: https://doi.org/10.1080/14783363.2019.1677151

Chaika, I. (2014). Standard ISO 9001:2015. What's waiting for us? Standards and Quality, 6(924), 60-63.

Crocker, K. J., \& Snow A. (2018). Theory of risk classification. In G. Dionne (Ed.), Handbook of Insurance (pp. 245-276). Retrieved from: https://link.springer.com/chapter/10.1007/978-94-010-0642-2 8

Crouhy, M. (2018). Fundamentals of risk management. Moscow, Russia: Yurait Publishing House.

Durivage, M. (2017). Integrating risk management in the quality management system - A primer. Retrieved from: https://www.pharmaceuticalonline.com/doc/integrating-risk-management-in-the-quality-managementsystem-a-primer-0001

Dzedik, V.A. (2015). Creation and audit of quality management systems in accordance with the international standard ISO 9001:2015. Volgograd, Russia: PrinTerra-Design.

Fonseca, L.M., \& Domingues, J. P. (2018). Empirical research of the ISO 9001:2015 transition process in Portugal: Motivations, benefits, and success factors. Quality Innovation Prosperity, 22(2), 16-64. DOI: http://dx.doi.org/10.12776/qip.v22i2.1099

Golubinsky, Y. M. (2016). Application of risk-based thinking in the new version of ISO 9001:2015. Monitoring. Control. Control, 2(16), 21-27. 
Hoodat, H., \& Rashidi, H. (2009). Classification and analysis of risks in software engineering. World Academy of Science, Engineering and Technology, 56, 446-452. Retrieved from: https://www.academia.edu/573832/Classification and Analysis of Risks in Software Engineering

Hopkin, P. (2017). Fundamentals of risk management: Understanding, evaluating and implementig effective risk management. 4th ed. London, England: Kogan Page.

Hutchins, G. (2014). Risk management - The future of quality management (translated by Rakhmanov V.) Retrieved from: https://1cert.ru/stati/upravlenie-riskami-budushchee-menedzhmenta-kachestva

International Organization of Standardization (ISO). (2018). ISO 31000:2018 Risk management. Principes and guidelines. Geneve, Switzerland: ISO. Retrieved from: https://www.risk-academy.ru/

Itkin, B. (2016). Risk and risk-based thinking: Whether we can control the first with the second? Standards and Quality, 10(952), 68-73.

Levshin, L. M. (2015). Application of the risk-based approach at the industrial enterprises. Science Perspectives, $3(66), 162-167$.

Mire-Sluis, A., Ramnarine E., Siemiatkoski, J., Weese, D., Swann, P., O'Keeffe, R., Kutza, J., Edwards, J., \& McLeod, L. D. (2010). Practical applications of quality risk management. Retrieved from: https://mafiadoc.com/practicalapplications-of-quality-risk-management- casss 5a4644711723dd0698313138.html

Molach, H. A., Long, M., \& Bisman, G. S. (2015). Risk management. Foreign experience. Quality Management Methods, 5, 26-32.

Orlova, O. A. (2018). Improvement of quality management systems of organizations on the basis of development of risk-based models. (Doctoral thesis). St. Petersburg, Russia: St. Petersburg State University of Economics. Retrieved from: http://unecon.ru/sites/default/files/d04orlovaoy.pdf

Panasyuk, V. N. (2015). Integrated risk management in JSC NIIME and "Mikron" company. Quality Management Methods, 4, 10-15.

Ralexandrov, S., Timofeeva, N., Zorin, Y., \& Novikov, V. (2017). Risk-based thinking and process approach to activity management. Advances in Chemistry and Chemical Technology, 10(964), 71-75.

Redko, L., \& Yanushevskaya, M. (2018). Risk analysis in the quality management system. Standards and Quality, 6(972), 98-102.

Renn, O. (2010). Concepts of risk: A classification. Retrieved from: https://mafiadoc.com/queue/concepts-of-riska-classification 5af80b8a7f8b9a53378b4667.html

Rybski, C., Jochem, R., \& Homma, L. (2017), Empirical study on status of preparation for ISO 9001:2015. Total Quality Management \& Business Excellence, 28(9-10), 1-14. DOI: https://doi.org/10.1080/14783363.2017.1303886

Smith, C., Kourouklis, A., \& Cano, M. (2018). ISO 9001: 2015 introduction of explicit risk-based thinking - Benefit or limitation? Asigurarea Calitatii Quality Assurance, 24(94), 29-40.

Retrieved from: http://www.asigurareacalitatii.ro/wp-content/uploads/94-29.pdf

Spiridonova, A. A., \& Khomutova, E. G. (2017). The risk-oriented approach in the quality management system of an industrial enterprise: The problem of selectiiing the methods of risk management, ОРГАНИЗАТОР ПРОИЗВОДСТВА, 25(2), 92-100. DOI: https://dx.doi.org/10.25065/1810-4894-2017-25-2-92-100

Standartinform. (2015). GOST R ISO 9001-2015. Quality Management Systems. Requirements. Moscow, Russia: Standartinform.

Standartinform. (2016). GOST R 57189-2016/ISO/TS 9002:2016. Quality management systems for the use of ISO9001:2015. Moscow, Russia: Standartinform.

Ukolov, A. I. (2017). Risk assessment. 2nd stereotype edition. Moscow, Russia: Direct Media. Retrieved from: http://biblioclub.ru/index.php?page=book\&id=445268

Vaz Pereira, G., Severo, F., \& Fontoura, L. (2016). A risk management approach based on situational method engineering. Retrieved from: https://mafiadoc. com/a-risk-management- approach-based-on-semanticscholar 59e5a3e01723dd4fd1925367.html

Zhemchugova, O. V., \& Levshina, V. V. (2018). Approbation of the methodological approaches to the choice of the risk-based thinking application method in the quality management system of an organization. Economics and Entrepreneurship, 11, 871-875.

Zhemchugova, O. V., Levshina, V. V., \& Levshin, L. M. (2017). Choice of the risk-based thinking application method in the organization. Economics and Entrepreneurship, 11, 1063-1066. 